\title{
Criptógamos do Parque Estadual das Fontes do Ipiranga, São Paulo, SP, Brasil. Algas, 33: Chlorophyceae (famílias Palmellaceae, Hormotilaceae e Dictyosphaeriaceae)
}

\author{
Carlos Eduardo de Mattos Bicudo ${ }^{1,2}$
}

Recebido: 12.01.2011; aceito: 19.11.2012

\begin{abstract}
Cryptogams from Parque Estadual das Fontes do Ipiranga, São Paulo, São Paulo State, Brazil. Algae, 33: Chlorophyceae (families Palmellaceae, Hormotilaceae, and Dictyosphaeriaceae)). Floristic survey of families Palmellaceae, Hormotilaceae, and Dictyosphaeriaceae (Chlorophyceae) from Parque Estadual das Fontes do Ipiranga, São Paulo, São Paulo State, southeast Brazil. Eight genera, 9 species and 1 variety that is the typical of its respective species were identified. Dictyosphaeriaceae is the family taxonomically better represented in the area, represented by 4 genera and 6 species followed by Hormotilacae and Palmellaceae with 2 genera and 2 species each family. Botryococcus and Dictyosphaerium are the genera with the largest number of species (2) in the area, and Dictyosphaerium pulchellum the best geographically represented taxon, occurring in 5 localities, followed by Dimorphococcus lunatus in 3 localities, Botryococcus braunii and Sphaerocystis schroeteri in 2 localities; and B. protuberans var. protuberans, Hormotilopsis gelatinosa, Westella botryoides, Ecballocystis fritschii, Dictyosphaerium ehrenbergianum Nägeli and Palmella aurantia the least represented ones, occurring in a single locality each.
\end{abstract}

Key words: Brazil, Dictyosphaeriaceae, Hormotilaceae, Palmellaceae

RESUMO - (Criptógamos do Parque Estadual das Fontes do Ipiranga, São Paulo, SP, Brasil. Algas, 33: Chlorophyceae (famílias Palmellaceae, Hormotilaceae e Dictyosphaeriaceae)). Levantamento florístico das Palmellaceae, Hormotilaceae e Dictyosphaeriaceae (Chlorophyceae) do Parque Estadual das Fontes do Ipiranga, Município e Estado de São Paulo, Brasil sudeste. Foram identificados oito gêneros, nove espécies e uma variedade típica de sua respectiva espécie. Dictyosphaeriaceae foi a família taxonomicamente melhor representada na área, representada por quatro gêneros e seis espécies, seguida por Hormotilacae e Palmellaceae com dois gêneros e duas espécies cada família. Botryococcus e Dictyosphaerium foram os gêneros representados pelo maior número de espécies (2) e Dictyosphaerium pulchellum a espécie que apresentou a maior distribuição geográfica na área do PEFI, ocorrendo em cinco localidades. Dimorphococcus lunatus ocorreu em três localidades, Botryococcus braunii e Sphaerocystis schroeteri em duas e B. protuberans var. protuberans, Hormotilopsis gelatinosa, Westella botryoides, Ecballocystis fritschii, Dictyosphaerium ehrenbergianum Nägeli e Palmella aurantia em uma localidade cada uma.

Palavras-chave: Brasil, Dictyosphaeriaceae, Hormotilaceae, Palmellaceae

\section{Introdução}

O conhecimento das famílias Palmellaceae, Hormotilaceae e Dictyosphaeriaceae no PEFI, Parque Estadual das Fontes do Ipiranga, está distribuído em 13 trabalhos, dos quais seis são de cunho taxonômico e os demais sete de cunho ecológico. Estes últimos apenas relacionam representantes das duas famílias nas listas do material identificado, utilizando os nomes para a interpretação da ecologia da comunidade planctônica ou perifítica.
Bohlin (1897) é a primeiro trabalho a mencionar a ocorrência de representante das famílias Palmellaceae e Dictyosphaeriaceae no Brasil. O referido autor identificou parte do material coletado por Gustav Malme, no período de 19 de setembro de 1892 a 06 de agosto de 1894, durante a $1^{\text {a }}$ Expedição Regnell por território brasileiro e paraguaio. Não existe informação em Bohlin (1897) sobre as amostras no que tange ao tipo de hábitat amostrado e onde as amostras estudadas se encontram depositadas. Palmella mucosa Kützing, Dictyosphaerium pulchellum Wood, Dimorphococcus

1. Instituto de Botânica, Núcleo de Pesquisa em Ecologia, Caixa Postal 68041, 04045-972 São Paulo, SP, Brasil

2. Autor para correspondência: cbicudo@terra.com.br 
lunatus A. Braun foram referidos nesse trabalho como ocorrendo, respectivamente, em Cuiabá no Estado de Mato Grosso, Corumbá no Estado de Mato Grosso do Sul e Pelotas no Estado do Rio de Janeiro. Os três nomes acima são correntemente aceitos.

Leite (1974) descreveu e ilustrou 20 gêneros de Chlorococcales para a área do PEFI situado na cidade de São Paulo, incluindo 49 espécies, 12 variedades e três formas taxonômicas que não são as típicas de suas respectivas espécies e variedades. Três dessas espécies (Botryococcus braunii Kützing, Dictyosphaerium pulchellum Wood e Dimorphococcus lobatus A. Braun) são representantes da família Dictyosphaeriaceae. Sant'Anna (1984) inventariou as Chlorococcales do Estado de São Paulo incluindo 66 gêneros, 178 espécies, 24 variedades que não são as típicas de suas respectivas espécies e cinco formas igualmente não típicas, porém, de suas respectivas variedades. Dos gêneros, apenas Dictyosphaerium e Dimorphococcus, com uma espécie cada um, respectivamente, D. pulchellum Wood e D. lunatus A. Braun foram documentados como ocorrendo na área do PEFI. Botryococcus braunii Kützing que havia sido identificado por Leite (1974) para o PEFI não teve material desta última localidade estudado por Sant'Anna (1984). Sant'Anna et al. (1989) estudaram a ficoflórula do Lago das Garças, incluindo informação sobre $\mathrm{pH}$, profundidade, transparência da água, floração e as algas identificadas. Da parte taxonômica, as referidas autoras incluíram breves descrições, medidas e ilustrações dos materiais identificados, que são nas famílias ora estudadas os seguintes: Sphaerocystis schroeteri Chodat (Palmellaceae), Botryococcus braunii Kützing, B. protuberans West \& West, Dictyosphaerium ehrenbergianum Nägeli e D. pulchellum Wood (Botryococcaceae $=$ Dictyosphaeriaceae). Ferragut et al. (2005) referiram a presença de Dictyosphaerium pulchellum Wood no Lago do IAG e Tucci et al. (2006) estudaram a composição florística do Lago das Garças e identificaram a ocorrência de Botryococcus braunii Kützing, B. protuberans (West \& West) De-Wildeman var. protuberans, Dictyospherium ehrenbergianum Nägeli, D. pulchellum Wood e Sphaerocystis schroeteri Chodat. Contudo, no último trabalho não constam descrição nem ilustração dos materiais identificados.

Entre os trabalhos de cunho ecológico, Bicudo et al. (1999) apenas relacionaram, sem descrever ou ilustrar, as espécies que haviam sido até então identificadas para o Lago das Garças e, entre elas,
Botryococcus braunii Kützing, B. protuberans (West \& West) De-Wildeman, Dictyospherium ehrenbergianum Nägeli, D. pulchellum Wood, Sphaerocystis schroeteri Chodat e Westella botryoides (West \& West) De-Wildeman. Ainda para o Lago das Garças, Gentil (2000) identificou Botryococcus braunii Kützing, Dictyosphaerium ehrenbergianum Nägeli, D. pulchellum Wood e Sphaerocystis schroeteri Chodat, mas apenas do segundo forneceu descrição bastante sucinta, medidas e ilustração; Vercellino (2001) identificou Botryococcus braunii Kützing, B. protuberans (West \& West) De-Wildeman (sem especificar a variedade), Dictyospherium ehrenbergianum Nägeli, D. pulchellum Wood e Dicyosphaerium sp.; Tucci (2002) apenas relacionou, sem descrever nem ilustrar as mesmas quatro espécies acima referidas por Gentil (2000) e Westella botryoides (West \& West) De-Wildeman; Crossetti (2002) trabalhou com mesocosmos e identificou Dictyosphaerium ehrenbergianum Nägeli, D. pulchellum Wood e Westella botryoides (West \& West) De-Wildeman; Fonseca (2005) identificou Botryococcus braunii Kützing, Dictyosphaerium ehrenbergianum Nägeli, D. pulchellum Wood, Sphaerocystis schroeteri Chodat e Westella botryoides (West \& West) De-Wildeman para o Lago das Garças e Botryococcus braunii Kützing e Dictyosphaerium pulchellum Wood para o Lago das Ninféias sem, contudo, descrever e/ou ilustrar esses materiais; finalmente, Crossetti (2006) identificou a estrutura da comunidade fitoplanctônica do Lago das Garças ao longo de um período de oito anos e identificou Botryococcus braunii Kützing, Dictyosphaerium ehrenbergianum Nägeli e D. pulchellum Wood.

Leite (1974) é o trabalho de maior abrangência taxonômica que foi publicado sobre material do PEFI, entretanto, número muito maior de coletas foi providenciado na área do Parque desde então. Além disso, quantidade significativa de modificações nomenclaturais ocorreu durante os 34 anos que vão desde a publicação do trabalho de Leite (1974) até hoje. Por essas duas razões foi realizado o atual levantamento.

\section{Material e métodos}

Os métodos para coleta, preservação e estudo do material empregados no presente trabalho constam em Bicudo \& Menezes (2006). Todas as amostras, seja de perifíton seja de fitoplâncton, encontram-se depositadas no Herbário Científico do Estado "Maria 
Eneyda P. Kauffmann Fidalgo" (SP) do Instituto de Botânica da Secretaria do Meio Ambiente do Estado de São Paulo.

Visando sua fácil localização, gêneros, espécies e variedades taxonômicas foram relacionadas em ordem alfabética crescente, sendo as variedades dentro de suas respectivas espécies e estas dentro dos gêneros competentes. Espécies e variedades que só constam da literatura, isto é, que não foram reencontradas durante o presente levantamento, tiveram seus nomes precedidos por um asterisco tanto nas chaves de identificação quanto no texto. O sistema de classificação adotado foi o de Bourrelly (1990), por ser o único que inclui todos os gêneros até então conhecidos, os quais foram classificados segundo critérios uniformemente aplicados a todo o universo dos gêneros nele contidos.

\section{Resultados e Discussão}

Os oito gêneros presentemente identificados para o PEFI têm a seguinte situação sistemática:

Divisão Chlorophyta

Classe Chlorophyceae

Ordem Chlorococcales

Família Dictyosphaeriaceae

Botryococcus

Dictyosphaerium

Dimorphococcus

Westella

Família Hormotilaceae

Ecballocystis

Hormotilopsis

Família Palmellaceae

Palmella

Sphaerocystis

\section{DICTYOSPHAERIACEAE}

Indivíduos unicelulares de hábito cenobial, em que as células possuem arranjo definido no cenóbio. As células reúnem-se através de restos mucilaginosos da parede da célula-mãe e pode ou não existir um envoltório mucilaginoso comum. As células têm forma esférica, elipsoidal, ovoide, reniforme ou cordiforme. O cloroplastídio é único ou pode estar presente em número de dois; ter forma laminar, poculiforme ou, raramente, estrelado e posição parietal; e pode ou não possuir um pirenoide. A parede celular é sempre lisa. A reprodução assexuada é feita por autósporos ou zoósporos e a sexuada é do tipo oogâmico e ocorre somente em alguns gêneros.

Chave para os gêneros de Dictyosphaeriaceae

1. Cenóbio compacto; células ovoides distribuídas na periferia da mucilagem, pólo arredondado voltado para o exterior, em geral não envolto pela mucilagem colonial ... Botryococcus

1. Cenóbio frouxo; células esféricas ou quase, totalmente imersas na mucilagem colonial

2. Grupo de 4 células situadas muito próximas umas das outras, deixando um meato central quadrangular Westella

2. Grupo de 4 células situadas mais ou menos distantes umas das outras, não deixando um meato central quadrangular 3. Células de duas formas em cada grupo de 4 ( 2 elipsoides e 2 reniformes) Dimorphococcus

3. Células de uma só forma em cada grupo de 4 Dictyosphaerium

\section{Botryococcus Kützing}

Indivíduos cenobiais. Cenóbios formados por elevado número de células densamente distribuídas na periferia de um envoltório mucilaginoso abundante e, em geral, impregnado por sais de ferro, que lhe confere coloração desde amarelo-palha até castanho escuro. As células podem ser aproximadamente esféricas ou ovoides. Em B. protuberans, parte da célula está mergulhada na mucilagem colonial, parte não (quando a célula é ovoide, o pólo arredondado fica fora da mucilagem), enquanto que em $B$. braunii toda a célula está imersa na mucilagem colonial. O cloroplastídio é único por célula, ocupa posição parietal e tem forma de copo (poculiforme) ou de lâmina lobada, com uma estrutura semelhante a um pirenoide em sua região central, porém, nua. Já foi, contudo, provada a existência de amido nos plastídios.

\section{Chave para as espécies de Botryococcus}

1. Cenóbios com mais de 64 células; células densamente distribuídas na mucilagem cenobial; mucilagem cenobial envolvendo totalmente as células . B. braunii

1. Cenóbios com até 64 células; células frouxamente distribuídas na mucilagem cenobial; mucilagem cenobial envolvendo só a parte da célula voltada para o interior do cenóbio ......... * B. protuberans var. protuberans 
B. braunii Kützing, Species algarum. 892. 1849. Figuras 1-2

Cenóbios globosos, compostos por numerosos grupos (em geral $>64$ células) de 4 células unidos entre si por fios de mucilagem, 56-150 $\mu \mathrm{m}$ diâm.; mucilagem colonial em geral castanho escuro, envolvendo completamente as célula; células elípticas, densamente distribuídas em 1 só camada em torno da cavidade central, 7,2-9,8 $\mu \mathrm{m}$ compr., 5,2-6,5 $\mu \mathrm{m}$ larg.; cloroplastídio 1, parietal, poculiforme; pirenoide ausente.

Hábitat: plâncton no hidrofitotério (Sant'Anna 1984), Lago das Ninféias (Leite 1974, Fonseca 2005) e Lago das Garças (Sant'Anna 1984, Sant'Anna et al. 1989, Fonseca 2005, Crossetti 2006, Tucci et al. 2006); perifíton no Lago das Garças (Vercellino 2001).

A espécie é bastante comum no PEFI, ocorrendo em três dos principais corpos d'água do Parque.

* B. protuberans West \& West var. protuberans, Transactions and Proceedings of the Royal Society of Edinburg 41: 507, pl. 4, fig. 4, pl. 6, fig. 8-9. 1905.

Figura 3

Cenóbios globosos, compostos por poucos grupos (em geral $<64$ células) de 4 células unidos entre si por fios de mucilagem, 50-159,7 $\mu \mathrm{m}$ diâm.; mucilagem colonial em geral hialina, envolvendo apenas a parte das células voltada para a parte interior da colônia; células ovoides, frouxamente distribuídas em 1 só camada em torno da cavidade central, 11,8-19,5 $\mu \mathrm{m}$ compr., 8,1-13,4 $\mu \mathrm{m}$ larg.; cloroplastídio 1, parietal, poculiforme ?; pirenoide ausente.

Hábitat: plâncton no Lago das Garças (Tucci et al. 2006); perifíton no Lago das Garças (Vercellino 2001).

Sant'Anna (1984) referiu a ocorrência da var. minor G.M. Smith desta espécie em algumas localidades do Estado de São Paulo. A única diferença entre esta variedade e a típica da espécie está unicamente no tamanho de suas células. Há, entretanto, um pequeno recobrimento entre os menores tamanhos das células da variedade-tipo da espécie e os maiores da var. minor G.M. Smith. Komárek \& Fott (1983) reconhecem a existência da var. minor G.M. Smith, mas o Algaebase não a refere nem como sinônimo.

\section{Dictyosphaerium Nägeli}

Indivíduos cenobiais, de vida livre. Os cenóbios são constituídos por quatro grupos de quatro células cada um, os quais são reunidos pelos remanescentes gelatinizados da parede celular da célula-mãe que irradiam de um centro comum, formando uma estrutura cruciada. Estes cenóbios podem estar envoltos por uma mucilagem comum, uniforme, mais ou menos ampla e podem também se reunir em cenóbios múltiplos. As células podem ser esféricas ou elipsoidais. Existe apenas um cloroplastídio em forma de copo (poculiforme) por célula, com um pirenoide situado mais ou menos na porção central do plastídio.

A identificação taxonômica dos representes de Dictyosphaerium é facilitada porque após a liberação da parede da célula-mãe, os autósporos permanecem juntos, unidos uns aos outros por filamentos resultantes da gelatinização parcial da parede da célula-mãe.

Chave para as espécies de Dictyosphaerium

1. Células elipsoides a pouco ovoides; restos da parede da célula-mãe sob a forma de filamentos inseridos lateralmente, próximo do ápice da célula D. ehrenbergianum

1. Células esféricas; restos da parede da célulamãe sob a forma de filamentos inseridos apicalmente na célula D. pulchellum

D. ehrenbergianum Nägeli, Gattungen einzelliger Algae physiologisch und systematisch bearbeitet. 74, pl. 2, fig. E. 1849.

Figura 4

Cenóbios esféricos a irregulares, constituídos por 1 a vários grupos de 4 células, filamentos de mucilagem inseridos lateralmente, próximo do ápice da célula; células elipsoides a pouco ovoides, 5-7,2 $\mu \mathrm{m}$ long., 3-6,5 $\mu \mathrm{m}$; cloroplastídio 1, parietal, poculiforme; pirenoide 1, aproximadamente central no plastídio; parede celular fina.

Hábitat: plâncton no Lago das Garças (Tucci et al. 2006).

Dictyosphaerium ehrenbergianum Nägeli difere de D. pulchellum H.D. Wood, mais do que tudo, pelos filamentos de mucilagem que unem as células de cada cenóbio estarem inseridos lateralmente, próximo do ápice da célula; além disso, pela forma das células, que na primeira espécie é elipsoide assimétrica ou ovoide, enquanto que na segunda é esférica.

D. pulchellum H.D. Wood, Smithsonian Contributions to Knowledge 19(241): 84, pl. pl. 10, fig. 4. 1874. Figuras 5-6

Cenóbios esféricos a ovoides, constituídos por 1 a vários grupos de 4 células, filamentos de mucilagem inseridos no ápice da célula; células esféricas, 

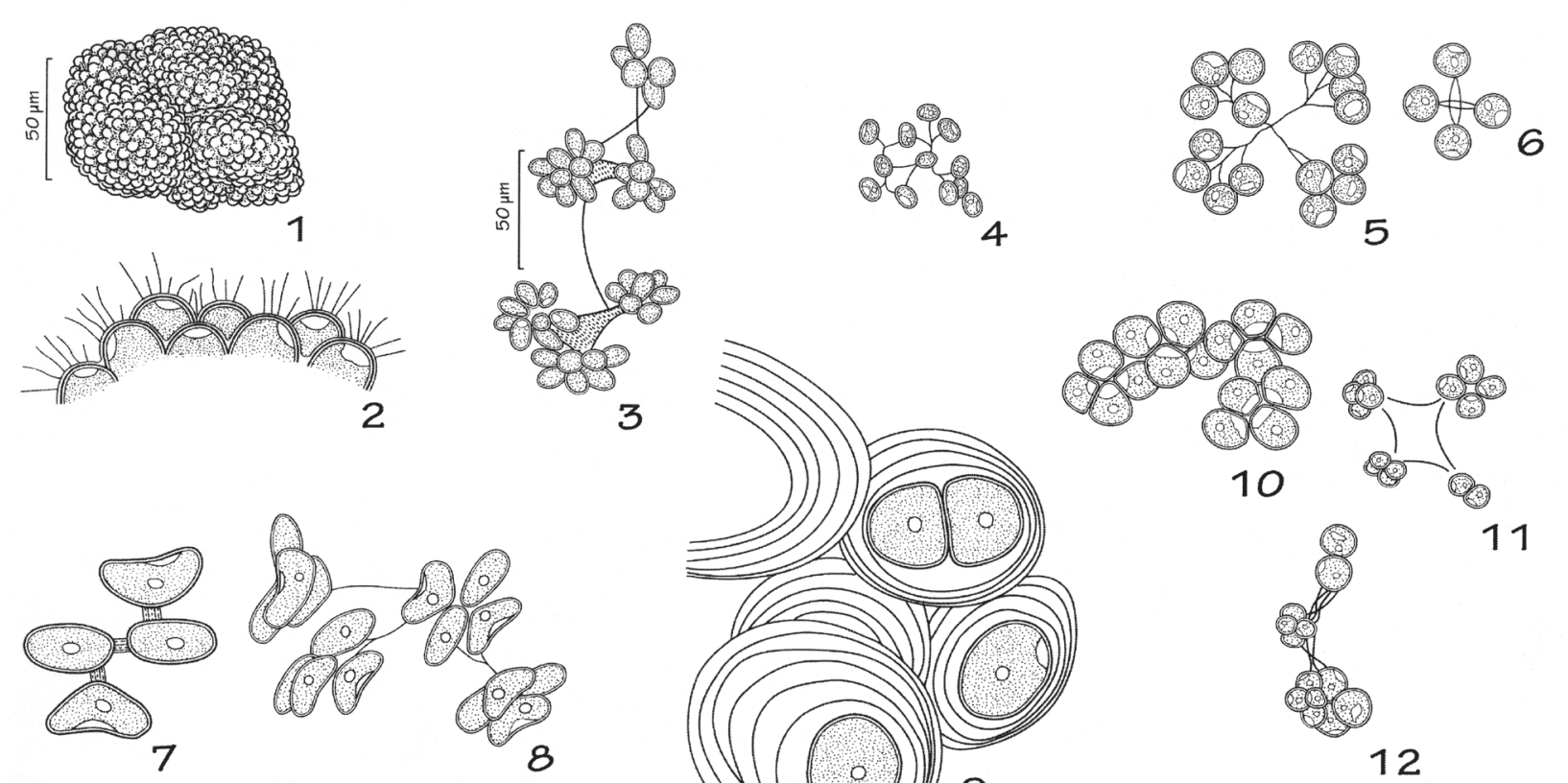

3
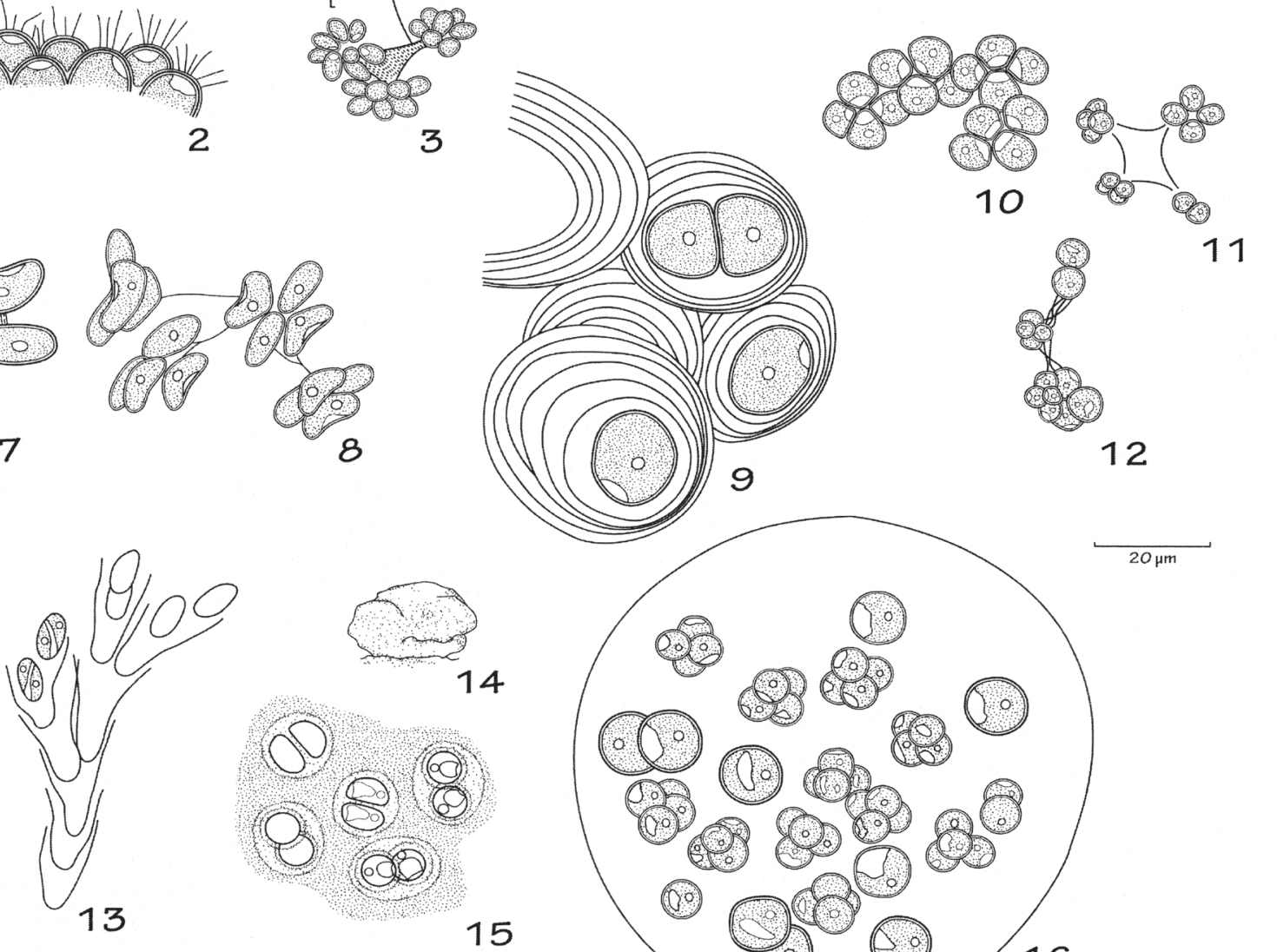

4

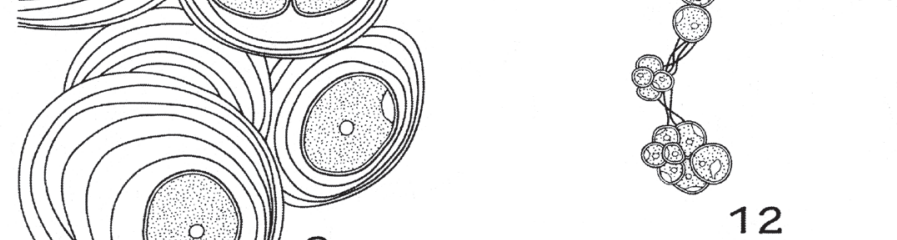

12

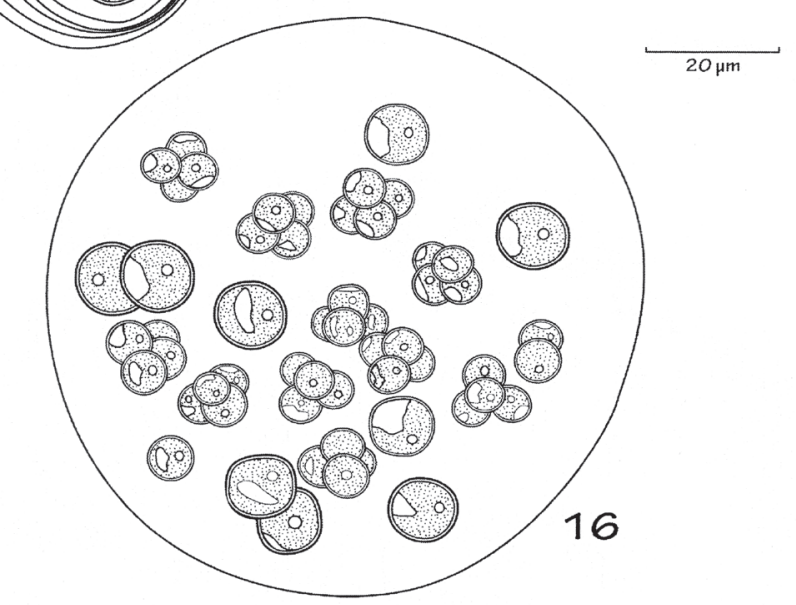

Figuras 1-2. Botryococcus braunii (de Sant'Anna 1984). Figura 3. Botryococcus protuberans var. protuberans (de Sant'Anna 1984). Figura 4. Dictyosphaerium ehrenbergianum (de Sant'Anna 1984). Figuras 5-6. Dictyosphaerium pulchellum (de Sant'Anna 1984). Figuras 7-8. Dimorphococcus lunatus (de Sant'Anna 1984). Figura 9. Hormotilopsis gelatinosa. Figuras 10-12. Westella botryoides (de Sant'Anna 1984). Figura 13. Ecballocystis fritschii (de Bicudo \& Menezes 2006). Figuras 14-15. Palmella aurantia. 14. Aspecto macroscópico da alga. Figura 16. Sphaerocystis schroeteri (de Sant'Anna 1984). Barra de escala $=20 \mu \mathrm{m}$.

Figures 1-2. Botryococcus braunii (from Sant'Anna 1984). Figure 3. Botryococcus protuberans var. protuberans (from Sant'Anna 1984). Figura 4. Dictyosphaerium ehrenbergianum (from Sant'Anna 1984). Figures 5-6. Dictyosphaerium pulchellum (from Sant'Anna 1984). Figures 7-8. Dimorphococcus lunatus (from Sant'Anna 1984). Figure 9. Hormotilopsis gelatinosa. Figures 10-12. Westella botryoides (from Sant'Anna 1984). Figure 13. Ecballocystis fritschii (from Bicudo \& Menezes 2006). Figures 14-15. Palmella aurantia. 14. Naked eye view of alga. Figure 16. Sphaerocystis schroeteri (from Sant'Anna 1984). Scale bar $=20 \mu \mathrm{m}$. 
4-6,2 $\mu \mathrm{m}$ larg.; cloroplastídio 1, parietal, poculiforme; pirenoide 1, aproximadamente central no plastídio; parede celular fina.

Hábitat: plâncton no reservatório sem nome próximo do Lago das Garças (SP115374; Sant'Anna et al. 1989), no Lago das Garças (SP114661, SP115383; Bicudo et al. 1999, Gentil 2000, Tucci 2002, Crossetti 2002, Tucci et al. 2006), no Lago das Ninféias (SP115384), no hidrofitotério (SP114600), no Lago da Nascente (SP114654) e em um reservatório sem nome localizado além do Lago dos Cisnes (SP115006), em um reservatório sem indicação precisa, provavelmente o Lago das Garças (Sant'Anna 1984); perifíton no Lago das Garças (Vercellino 2001).

Dictyosphaerium pulchellum H.C. Wood difere de D. ehrenbergianum Nägeli, principalmente, pelos filamentos de mucilagem que unem as células de cada cenóbio estarem inseridos apicalmente na célula; também, pela forma das células, que na primeira é esférica e na segunda elipsoide assimétrica ou ovoide.

\section{Dimorphococcus A. Braun}

Indivíduos cenobiais, de vida livre. Os cenóbios são mais ou menos globosos e formados por grupos de quatro células reunidas por remanescentes gelatinizados da parede da célula-mãe. Às vezes, as células ocorrem envoltas por uma bainha comum de mucilagem homogênea. Cada grupo de quatro células tem duas delas de uma forma (ovoide) e duas de outra (reniforme ou cordiforme), donde o próprio nome do gênero. As células possuem um só cloroplastídio parietal, maciço, que envolve em uma maior ou menor extensão a periferia do protoplasma. $\mathrm{O}$ único pirenoide presente em cada célula pode ser facilmente identificado nas células jovens, porém, não nas adultas, onde está mascarado pela existência de grãos de amido.

Uma única espécie foi identificada.

\section{D. lunatus A. Braun, Algarum unicellularium genera} nova et minus cognita. 44. 1855.

Figuras 7-8

Cenóbios aproximadamente esféricos, constituídos por um ou mais grupos de 4 células, ligados por filamentos ramificados de mucilagem; células dispostas alternadamente, as 2 centrais oblongas, as 2 extremas reniformes a cordiformes,

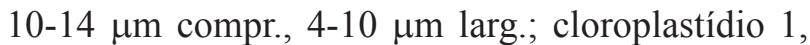
laminar, parietal, ocupando quase toda a periferia celular; pirenoide 1, mediano; parede celular delicada.
Hábitat: plâncton em um lago sem nome situado no meio de dois outros, entre os portões 1 e 2 do Jardim Botânico de São Paulo (SP114882; Leite 1974), no Lago do IAG (SP115128, SP115377; Leite 1974) e no hidrofitotério (SP130453; Sant'Anna 1984).

Dimorphococcus lunatus A. Braun é uma espécie bem circunscrita e, portanto, de fácil identificação taxonômica por conta dos cenóbios formados por duas células externas reniformes a cordiformes e duas internas oblongas.

\section{Westella De-Wildeman}

Os cenóbios são aproximadamente esféricos, livre-flutuantes, formados por grupos de quatro células cada um, arranjadas em cruz e dispostos um tanto desordenadamente no interior de mucilagem abundante. Os cenóbios 4-celulados unem-se uns aos outros por cordões de mucilagem resultantes da gelatinização da parede da célula-mãe, formando cenóbios múltiplos. Cada cenóbio múltiplo pode conter até uma centena de células. As células são esféricas e possuem um cloroplastídio poculiforme, parietal, com um pirenoide em sua porção basal.

Uma única espécie foi identificada.

W. botryoides (W. West) De-Wildeman, Bulletin de l'Herbier Boissier: sér. 1, 5: 532. 1897

= Tetracoccus botryoides $\mathrm{W}$. West, Journal of the Royal Microscopical Society 2: 735. 1892.

Figuras 10-12

Cenóbio plano, 4-celulado; célula esférica, distribuída em cruz deixando um pequeno espaço central, restos gelatinizados da parede da célula-mãe unindo os grupos de 4 células uns aos outros, 4-9,6 $\mu \mathrm{m}$ diâm.; cloroplastídio único, poculiforme, parietal; pirenoide 1, central.

Hábitat: plâncton no Lago das Garças (Sant'Anna et al. 1989, Fonseca 2005, Crossetti 2006, Tucci et al. 2006).

\section{HORMOTILACEAE}

Indivíduos cenobiais. Os cenóbios podem ser simples ou apresentar projeções laterais semelhantes a ramos; às vezes, têm aspecto dendroide, com as projeções laterais irregulares. As células distribuem-se sem qualquer ordem no interior da mucilagem cenobial ou podem situar-se na extremidade de restos da parede da célula-mãe. Em Ecballocystopsis, as células arranjam-se em uma série única, que pode "ramificar" dicotomicamente. As células podem ser 
globosas, elipsoidais ou cilíndricas. O cloroplastídio pode ser único por célula e ter forma urceolada ou estrelada, ou serem vários e terem forma discoide ou poligonal; em todos os casos sua posição é parietal na célula e pode ou não possuir um pirenoide. A parede celular é sempre lisa. A reprodução é feita por autósporos ou zoósporos.

Há divergência quanto à classificação desta família entre as Chlorococcales. Alguns de seus gêneros (Hormotila e Hormotilopsis) lembram, morfologicamente, outros da ordem Tetrasporales; Ecballocystis lembra formas de Oocystaceae; e Ecballocystopsis e Palmodictyon formas de Ulotrichales. Pouco se conhece ainda sobre a maioria de seus gêneros, a maioria dos quais monoespecífica, inclusive de seus processos reprodutivos, o que torna as Hormotilaceae uma família atualmente mal definida e bastante controvertida. Constituem um grupo totalmente artificial.

Chave para os gêneros de Hormotilaceae

1. Cenóbio filamentoso simple ou dendroide; células elipsoidais localizadas nas extremidades de tubos mucilaginosos estratificados ... Hormotilopsis

1. Cenóbio dendroide; células elipsoidais a quase cilíndricas localizadas em restos da parede da célula-mãe que assemelham vasos Ecballocystis

\section{Ecballocystis Bohlin}

Indivíduos reunidos em cenóbios mais ou menos arborescentes e, só muito raramente, ocorrem isolados. A célula tem forma elipsoide ou quase cilíndrica e existe sempre presa por um de seus pólos (posterior) a restos da parede da célula-mãe rompida, que assemelha um vaso. A continuação deste processo de reprodução leva à formação de uma colônia arborescente, em que os remanescentes das paredes celulares das células-mãe permanecem encaixados um na extremidade do outro. Ocorrem dois a vários cloroplastídios por célula, com forma laminar e posição lateral na célula. O pirenoide é único e situa-se mais ou menos centralmente em cada cloroplastídio. A parede celular é mais ou menos delgada, mas pode apresentar um espessamento nas duas extremidades.

$\mathrm{O}$ gênero foi descrito originalmente de material coletado sobre pedras, em um rio não identificado, em Cachoeira, Estado do Rio Grande do Sul. Ecballocystis pulvinata Bohlin foi a espécie descrita. O gênero é conhecido, atualmente, apenas do Brasil, da Índia e da
África do Sul, de localidades situadas todas na faixa tropical do globo terrestre.

Uma única espécie foi identificada.

* E. fritschii Iyengar, Annals of Botany 46: 222, pl. 8, fig. 8, fig. texto 4A-H, M-O, R-U. 1932.

Figura 13

Indivíduo formando cenóbios mais ou menos arborescentes, raro isolados; célula elipsoide a quase cilíndrica, fixa por um de seus pólos (posterior) a restos da parede da célula-mãe rompida, assemelhando um vaso, 20-25 $\mu \mathrm{m}$ compr., 7-10,5 $\mu \mathrm{m}$ larg.; cloroplastídios 2 a vários, laminares, laterais; pirenoide único, mais ou menos central em cada plastídio; parede celular mais ou menos delgada, podendo apresentar um espessamento em ambas extremidades.

Hábitat: perifíton no hidrofitotério (Bicudo \& Menezes 2006).

Ecballocystis fritschii Iyengar pode ser até facilmente reconhecida, conforme Komárek \& Fott (1983), pelo talhe macroscópico de seus cenóbios, que crescem prostrados sobre algum substrato. Os exemplares atualmente examinados jamais formaram uma massa macroscópica, visível a olho nu. Foram coletados sob a forma de cenóbios isolados, que cresciam prostrados sobre folhas de Nymphoides indicum Kuntze. Por outro lado, o remanescente da parede das células-mãe com a aparência de vaso amplamente aberto na extremidade distal permitiu diferir esta espécie de $H$. pulvinata Bohlin, que também forma massas macroscópicas.

\section{Hormotilopsis Trainor \& Bold}

Indivíduos descritos como filamentosos, cujos "filamentos" variam desde unisseriados e simples a até dendroides. Contudo, os "filamentos" são cenóbios em que as células situam-se nas extremidades de tubos mucilaginosos estratificados simples ou irregularmente "ramificados". A forma das células pode variar de esférica a elipsoidal. O cloroplastídio é urceolado, tem localização parietal e possui um pirenoide de tamanho bastante grande.

Os representantes deste gênero foram isolados de cultivos de solo dos Estados Unidos da América. Hormotilopsis é um gênero mono-específico, que difere de Hormotila somente pela existência de zoósporos tetraflagelados. Esta diferença não é fácil de ser observada na prática porque os zoósporos perdem rapidamente seus flagelos e secretam uma quantidade de mucilagem que cresce polarizada, formando uma 
estrutura tubular estriada, na extremidade da qual se localiza a célula.

A única espécie atualmente do gênero foi identificada.

H. gelatinosa Trainor \& Bold, American Journal of Botany 40: 758, fig. 1-19, 59. 1953.

Figura 9

Cenóbio dendroide formado por tubos ramificados, estriados de mucilagem; células arredondadas, 40-50 $\mu \mathrm{m}$ diâm. incl. mucilagem, 17-19 $\mu \mathrm{m}$ diâm. sem mucilagem; cloroplastídio 1, parietal, urceolado; pirenoide 1 .

Hábitat: perifíton no hidrofitotério (material não preservado).

Os indivíduos identificados apresentaram a célula sempre oblonga, mas a espécie pode incluir formas desde esféricas até elipsoides. Apresentaram também um plastídio apenas por célula, jamais fragmentado em pedaços, o que pode acontecer nas formas mais velhas da espécie. Finalmente, o maior número dos indivíduos apresentou-se isolado; só raramente formaram grupos de quatro ou cinco.

Esta é a segunda citação da ocorrência do gênero no Brasil. A primeira foi feita por Sant'Anna (1984), que o identificou de material planctônico coletado de um lago situado a $7 \mathrm{~km}$ a oeste da cidade de Jaú, no Estado de São Paulo.

\section{PALMELLACEAE}

Indivíduos cenobiais. Os cenóbios podem ser globosos (quando jovens) ou amorfos (quando mais velhas), em geral microscópicos, mas podem atingir tamanhos que permitem sua visualização a olho nu. As células têm forma esférica ou elipsoidal e distribuem-se em pares ou, mais raro, isoladas ou em grupos de quatro, sempre caoticamente no interior de uma mucilagem cenobial extremamente abundante. $\mathrm{O}$ cloroplastídio é único por célula, tem forma urceolada, situação parietal e pode ou não possuir um pirenoide. A parede celular é sempre lisa. A reprodução é feita por autósporos ou zoósporos.

Ogênero tem sido pouco coletado em todo o mundo. Os documentos de sua ocorrência são relativamente poucos. A maioria dos autores reconhece apenas uma espécie neste gênero ( $P$. aurantia $C$. Agardh), ao passo que outros dizem ser constituído por duas ou três espécies. Esta é, entretanto, uma pendência de difícil solução momentânea, dado o pouco conhecimento que se tem dessas espécies. Para complicar a situação, acrescente-se o fato de várias formas flageladas de outros gêneros (ex. Chlamydomonas) formarem, em seus ciclos-de-vida, estádios morfologicamente muito semelhantes aos representantes vegetativos de Palmella e que são, por isso, chamados estádios palmeloides, os quais podem ter sido descritos como espécies de Palmella.

Chave para os gêneros de Palmellaceae

1. Cenóbio microscópico, esférico ou elipsoidal ......... Sphaerocystis

1. Cenóbio macroscópico, amorfo Palmella

Palmella C. Agardh

Indivíduos formando cenóbios de aspecto irregular (sem forma definida) e, em geral, macroscópicos. As células possuem forma variável entre esférica e elipsoide e estão dispostas isoladas, aos pares ou em grupos de quatro no interior de uma mucilagem uniforme e bastante abundante. O cloroplastídio é único por célula, tem a forma de copo (poculiforme) ou urna (urceolado) e ocupa posição parietal na célula. Existe um pirenoide longitudinal, mediano em cada plastídio.

P. aurantia C. Agardh, Systema algarum. 15. 1824. Figuras 14-15

Cenóbio amorfo, formado por pares de células irregularmente distribuídos em mucilagem copiosa, homogênea; células esféricas, 12-15,5 $\mu \mathrm{m}$ diâm.; cloroplastídio único, urceolado, abertura irregular, parietal, 1 pirenoide mais ou menos central.

Hábitat: plâncton no hidrofitotério (material não preservado).

Discute-se se Palmella é um gênero monoespecífico e, neste caso, P. aurantia C. Agardh seria a única espécie nele classificada; ou se inclui, segundo Komárek \& Fott (1983), as três espécies seguintes: $P$. aurantia C. Agardh, P. miniata var. aequalis Nägeli sensu G.M. Smith e P. mucosa Kützing sensu Backhaus. Ainda segundo Komárek \& Fott (1983), Chlamydomonas lapponica Skuja e Palmella texensis Groover \& Bold também poderiam, dependendo de mais estudos, serem consideradas entre aquelas que constituem o gênero em pauta.

Palmella aurantia C. Agardh é bastante característica e até de fácil identificação taxonômica por conta da ocorrência isolada, aos pares ou em grupos de quatro, das células no interior de um envoltório mucilaginoso uniforme e extremamente abundante. 


\section{Sphaerocystis Chodat}

Indivíduos cenobiais. Os cenóbios são sempre microscópicos, esféricos, ricos em mucilagem envolvente e flutuam livremente na coluna d'água. As células são esféricas e aparecem reunidas em grupos de duas (raro) ou quatro (em geral), os quais estão distribuídos caoticamente no interior de uma mucilagem uniforme e abundante. As tétrades podem ser bastante regulares e ocupam a porção central do cenóbio. É comum encontrar tétrades jovens misturadas às mais velhas no mesmo cenóbio e isto pode ser facilmente visto pela diferença de tamanho das células das várias tétrades. O cloroplastídio é único por célula. Nas células jovens, ele tem a forma de copo (poculiforme) e ocupa posição parietal; nas células adultas, tornam-se maciços e forram, internamente, toda a parede celular. Existe um pirenoide longitudinal, mediano em cada plastídio.

S. schroeteri Chodat, Bulletin de l'Herbier Boissier 5:

119, pl. 9, fig. 1-12. 1897.

Figura 16

Cenóbio esférico, formado por 4-8-16-32 células irregularmente distribuídas em mucilagem homogênea, cenóbios-filhos geralmente presentes misturados aos adultos; células esféricas, 8-19,5 $\mu \mathrm{m}$ diâm.; cloroplastídio único, poculiforme nas células jovens ou maciço, preenchendo toda a face interna da parede celular nas células adultas; pirenoide 1, central.

Hábitat: plâncton no Lago das Ninféias (Fonseca 2005) e no Lago das Garças (Sant'Anna et al. 1989, Fonseca 2005, Crossetti 2006, Tucci et al. 2006).

Sphaerocystis schroeteri Chodat pode ser identificado com facilidade pela existência simultânea, no mesmo cenóbio composto, de cenóbios simples de idades diferentes, os quais podem ser distinguidos pelo tamanho distinto das células que constituem cada tétrade.

Esta espécie difere de S. planctonica (Koršikov) Bourrelly por que a última produz zoósporos, enquanto que $S$. schroeteri Chodat não. Fott (1974) não observou a presença de zoósporos no material que estudou e considerou S. planctonica (Koršikov) Bourrelly sinônimo heterotípico de S. schroeteri Chodat. Posição idêntica já havia sido assumida por Canter \& Lund (1968). Sant'Anna (1984) viu apenas a produção de autósporos no material de quatro localidades do Estado de São Paulo que examinou. Concluiu, por produzirem apenas autósporos, tratarem de espécimes de $S$. schroeteri Chodat.

Chave para identificação dos gêneros, espécies, variedades e formas taxonômicas das famílias Palmellaceae, Hormotilaceae e Dictyosphaeriaceae do PEFI

1. Cenóbio macroscópico, sem forma definida (Palmella) P. aurantia

1. Cenóbio microscópico, sem forma definida, dendroide, esférico ou elipsoidal

2. Cenóbio dendroide

3. Célula elipsoide a quase cilíndrica, fixa por um de seus pólos (posterior) a restos da parede da célula-mãe rompida, assemelhando um vaso . (Ecballocystis $) *$ E. fritschii

3. Cenóbio filamentoso simples ou irregularmente dendroide; células elipsoidais localizadas nas extremidades de tubos mucilaginosos estratificados.... (Hormotilopsis) H. gelatinosa

2. Cenóbio sem forma definida, esférico ou elipsoidal

4. Células dos cenóbios simples de várias idades no interior do envoltório mucilaginoso comum (Sphaerocystis) S. schroeteri

4. Células dos cenóbios simples sem diferença aparente de idades no interior do envoltório mucilaginoso comum

5. Cenóbio compacto; células ovoides distribuídas na periferia da mucilagem, pólo arredondado voltado para o exterior, em geral não envolto pela mucilagem colonial ....... (Botryococcus) 6. Cenóbio com mais de 64 células; células densamente distribuídas na mucilagem cenobial; mucilagem cenobial envolvendo totalmente as células B. braunii

6. Cenóbio com até 64 células; células frouxamente distribuídas na mucilagem cenobial; mucilagem cenobial envolvendo só a parte da célula voltada para o interior da cenóbio

5. Cenóbio frouxo; células esféricas ou quase, totalmente imersas na mucilagem colonial 
7. Grupo de 4 células situadas muito próximas umas das outras, deixando um meato central quadrangular (Westella) W. botryoides

7. Grupo de 4 células situadas mais ou menos distantes umas das outras, não deixando um meato central quadrangular 8. Células de duas formas em cada grupo de 4 ( 2 elipsoides, 2 reniformes)

(Dimorphococcus) D. lunatus

8. Células de uma só forma em cada grupo de 4 (Dictyosphaerium)

9. Células elipsoides a pouco avoides; restos da parede da célula-mãe sob a forma de filamentos inseridos lateralmente, próximo do ápice da célula D. ehrenbergianum

9. Células esféricas; restos da parede da célula-mãe sob a forma de filamentos inseridos apicalmente na célula D. pulchellum

Considerações finais - As famílias Dictyosphaeriaceae, Hormotilaceae e Palmellaceae estiveram representadas na área do PEFI, em conjunto, em oito ambientes distintos, quais sejam: seis reservatórios (Lago das Garças, Lago das Ninféias, Lago do IAG, lago situado próximo da Portaria 2 do Jardim Botânico de São Paulo, lago situado entre os dois da série de três situados entre as Portarias 1 e 2 do Jardim Botânico de São Paulo e lago situado acima do Lago dos Cisnes) e o hidrofitotério.

Os ambientes taxonomicamente mais ricos foram o hidrofitotério e o Lago das Garças, que apresentaram seis táxons cada um. Seguiu o Lago das Ninféias com três. Finalmente, o lago situado próximo da Portaria 2 do Jardim Botânico de São Paulo, o lago situado entre os dois da série de três que ficam entre as Portarias 1 e 2 do Jardim Botânico de São Paulo, o Lago do IAG e o lago situado acima do Lago dos Cisnes com um táxon cada um. Contudo, o lago situado próximo da Portaria 2 e aquele entre as Portarias 1 e 2 do Jardim Botânico de São Paulo são abastecidos, através de comportas, com água do Lago das Garças. De todos os sete ambientes mencionados neste trabalho, o Lago das Garças e o das Ninféias são os mais e melhor estudados de todos os localizados no PEFI. Consequentemente, o maior número de táxons encontrados nesses três ambientes em relação aos demais do PEFI pode ser simplesmente o resultado do maior esforço amostral neles realizado e, mais do que tudo, no Lago das Garças.

Quatro táxons [Dimorphococcus lunatus A. Braun, Westella botryoides (W. West) De-Wildeman, Palmella aurantia C. Agardh e Sphaerocystis schroeteri Chodat] foram coletados apenas do plâncton e outros dois (Hormotilopsis gelatinosa Trainor \& Bold e Ecballocystis fritschii Iyengar) apenas do perifíton. Três táxons (Botryococcus braunii Kützing, B. protuberans West \& West var. protuberans e Dictyosphaerium pulchellum H.D. Wood) foram coletados em um e outro tipo de ambiente. Tem ficado muito claro ao longo do atual inventário da ficoflórula do PEFI, a enorme importância de incluir amostragem nos dois tipos de ambiente, plâncton e perifíton, pois $40 \%$ dos táxons ora identificados ocorreu exclusivamente no plâncton, outros $20 \%$ só no perifíton e $30 \%$ tanto em um quanto em outro ambiente, o que vale dizer que, em última instância, a não-coleta de material perifítico incorreria na perda de $50 \%$ da riqueza taxonômica ora identificada.

A despeito de todo o esforço de busca, dos nove táxons atualmente identificados e que representam nove espécies, Ecballocystis fritschii Iyengar foi a única não reencontrada nas várias preparações feitas de material do hidrofitotério, isto é, do ambiente do qual proveio o material ora identificado, nem nas amostras preservadas e depositadas no Herbário Científico do Estado "Maria Eneyda P. Kauffmann Fidalgo". Estas amostras foram coletadas no período de março de 1972 a dezembro de 1977, fixadas e preservadas em solução de Transeau e serviram de base para a realização do trabalho de Sant'Anna (1984). Além destas amostras, várias outras foram coletadas de modo a cobrir as épocas chuvosa e quente e seca e fria que caracterizam a região, porém, a referida espécie jamais foi reencontrada.

\section{Agradecimentos}

$\mathrm{O}$ autor expressa seu melhor agradecimento ao $\mathrm{CNPq}$, Conselho Nacional de Desenvolvimento Científico e Tecnológico, por bolsa de produtividade (processo no 309474/2010-8). 


\section{Literatura citada}

Algaebase. 2012. Listing the World's Algae. -://www. algaebase.org (acesso em 30.09.2012).

Bicudo, C.E.M. \& Menezes, M. 2006. Gêneros de algas de águas continentais do Brasil: chave para identificação e descrições. $2^{\mathrm{a}}$ ed. RiMa Editora, São Carlos.

Bicudo, C.E.M., Ramírez R., J.J., Tucci, A. \& Bicudo, D.C. 1999. Dinâmica de populações fitoplanctônicas em ambiente eutrofizado: o Lago das Garças, São Paulo. In: R. Henry (ed.). Ecologia de reservatórios: estrutura, função e aspectos sociais. Fundação de Amparo à Pesquisa do Estado de São Paulo e Fundação do Instituto de Biociências, Botucatu, p. 408-448.

Bohlin, K. 1897. Die Algen der ersten Regnell'schen Expedition, 1: Protococcoideen. Bih K svenska Vetensk Handl. 23: 1-46.

Bourrelly, P. 1990. Les algues d'eau douce: initiation à la systématique, 1: Chlorophycées, v.1, 2ª ed. Éditions N. Boubée, Paris.

Canter, H.M. \& Lund, J.W.G. 1968. The importance of Protozoa in controlling the abundance of planktonic algae in lakes. Proceedings of the Linnean Society of London 179: 203-219.

Crossetti, L.O. 2002. Efeitos do empobrecimento experimental de nutrientes sobre a comunidade fitoplanctônica em reservatório eutrófico raso, Lago das Garças, São Paulo. Dissertação de Mestrado, Universidade de São Paulo, Ribeirão Preto.

Crossetti, L.O. 2006. Estrutura e dinâmica da comunidade fitoplanctônica no período de oito anos em ambiente eutrófico raso (Lago das Garças), Parque Estadual das Fontes do Ipiranga, São Paulo. Tese de Doutorado, Universidade de São Paulo, Ribeirão Preto.

Ferragut, C., Lopes, M.R.M., Bicudo, D.C., Bicudo, C.E.M. \& Vercellino, I.S. 2005. Ficoflórula perifítica e planctônica (exceto Bacillariophyceae) de um reservatório oligotrófico raso (Lago do IAG, São Paulo). Hoehnea 32: 137-184.
Fonseca, B.M. 2005. Diversidade fitolanctônica como discriminador ambiental em dois reservatórios rasos com diferentes índices de trofia no Parque Estadual das Fontes do Ipiranga, São Paulo, SP. Tese de Doutorado, Universidade de São Paulo, São Paulo.

Fott, B. 1974. Taxonomie der Palmelloiden Chlorococcales (Familie Palmogloeaceae). Preslia 46: 1-31.

Gentil, R.C. 2000. Variação sazonal do fitoplâncton em um lago subtropical eutrófico e aspectos sanitários, São Paulo, SP. Dissertação de Mestrado, Universidade de São Paulo, São Paulo.

Komárek, J. \& Fott, B. 1983. Chlorophyceae (Grünalgen), Ordnung Chlorococcales. In: G. Huber-Pestalozzi (ed.). Das Phytoplankton des Süsswassers. E. Schweizerbart'sche Verlagsbuchhandlung (Nägele und Obermiller), Stuttgart.v.7(1), pp. 1-1044.

Leite, C.R. 1974. Contribuição ao conhecimento das Chlorococcales (Chlorophyceae) planctonicas do Parque Estadual das Fontes do Ipiranga, São Paulo, Brasil. Dissertação de Mestrado, Universidade de São Paulo, São Paulo.

Sant'Anna, C.L. 1984. Chlorococcales (Chlorophyceae) do Estado de São Paulo, Brasil. Bibliotheca Phycologica 67: 1-348.

Sant'Anna, C.L., Azevedo, M.T.P. \& Sormus, L. 1989. Fitoplâncton do Lago das Garças, Parque Estadual das Fontes do Ipiranga. São Paulo, SP, Brasil: estudo taxonômico e aspectos ecológicos. Hoehnea 16: 89-131.

Tucci, A. 2002. Sucessão da comunidade fitoplanctônica de um reservatório urbano e eutrófico, São Paulo, SP, Brasil. Tese de Doutorado, Universidade Estadual Paulista, Rio Claro.

Tucci, A., Sant'Anna, C.L., Gentil, R.G. \& Azevedo, M.T.P. 2006. Fitoplâncton do Lago das Garças, São Paulo, Brasil: um reservatório urbano eutrófico. Hoehnea 33: 147-175.

Vercellino, I.S. 2001. Sucessão da comunidade de algas perifíticas em dois reservatórios do Parque Estadual das Fontes do Ipiranga, São Paulo: influência do estado trófico e período climatológico. Dissertação de Mestrado, Universidade Estadual Paulista, Rio Claro. 
